\title{
Incidência de Parasitóides e Patógenos em Adultos de Diabrotica speciosa (Germ.) (Coleoptera: Chrysomelidae) na Região de Pelotas, RS
}

\author{
Maria A. Heineck-Leonel ${ }^{1}$ e Luiz A. B. Salles ${ }^{1}$
}

${ }^{1}$ CPACT/EMBRAPA, Caixa postal 403, 96001.970, Pelotas, RS.

An. Soc. Entomol. Brasil 26(1): 81-85 (1997)

Incidence of Parasitoids and Pathogens in Adults of Diabrotica speciosa (Germ.) (Coleoptera: Chrysomelidae) in Pelotas, RS

\begin{abstract}
A survey of natural enemies of Diabrotica speciosa (Germ.) adults collected on different vegetable crops in Pelotas, RS (lat. $31^{\circ}, 52^{\prime} \mathrm{S}$, long. $52^{\circ}, 21 ' \mathrm{~W}$ ) was conducted. The most frequent natural enemies were the tachinid Celatoria bosqi Blanch., the braconid Centistes gasseni Shaw and the fungus Beauveria bassiana (Bals.) Vuill. The nematode Hexamermis sp. and the fungus Metarhizium anisopliae (Metsch.) Sorok. occurred at low levels. The lowest percentage of parasitism was observed in December (6.6\%) and the highest in April (35.5\%), with an yearly average of ca. $20 \%$.
\end{abstract}

KEY WORDS: Insecta, bean leaf beetle, natural enemies, biological control.

RESUMO - O trabalho teve por objetivo identificar e quantificar os inimigos naturais de adultos de Diabrotica speciosa (Germ.) coletados em diferentes plantas olerícolas entre maio de 1994 e abril de 1995 em Pelotas, RS (lat. 31 ${ }^{\circ}, 52$ 'S, long. $\left.52^{\circ}, 21^{\prime} \mathrm{W}\right)$. Os inimigos naturais mais freqüentes foram o taquinídeo Celatoria bosqi Blanch., o braconídeo Centistes gasseni Shaw e o fungo Beauveria bassiana (Bals.) Vuill. O nematóide Hexamermis sp. e o fungo Metarhizium anisopliae (Metsch.) Sorok. ocorreram em baixos níveis. Durante o ano, os menores percentuais de parasitismo foram observados no mês de dezembro $(6,6 \%)$ e os maiores em abril $(35,5 \%)$, resultando em um parasitismo médio anual em torno de $20 \%$.

PALAVRAS-CHAVE: Insecta, vaquinha, inimigos naturais, controle biológico.

A vaquinha Diabrotica speciosa (Germ.) é um crisomelideo polífago que danifica várias espécies de plantas olerícolas (Silva et al. 1968); os adultos alimentam-se de folhas e flores e as larvas de raízes. Seu controle é feito, principalmente, através de inseticidas. Os inimigos naturais da vaquinha têm sido estudados de maneira limitada, tanto em abrangência geográfica como nos níveis tróficos em que ocorre. Esta afirmação baseia-se no fato de que a maio- ria das referências bibliográficas limita-se a citar a ocorrência de parasitóides sem, contudo, quantificar sua importância (Tonet \& Reis 1979, Gassen 1986, Ferraz \& Monteiro 1987). A ocorrência do parasitóide Celatoria bosqi Blanch. (Diptera: Tachinidae), em adultos de D. speciosa no Uruguai foi relatada por Silva et al. (1968) e, na região de Passo Fundo, RS, por Gassen( 1986). Esta mesma espécie foi observada por Magalhães \& Quintela (1987), 
em Goiás, sobre adultos de Cerotoma arcuata Oliv. (Coleoptera: Chrysomelidae) em feijão caupi (Vigna unguiculata), causando reduções de até $32,2 \%$ na população. Hohmann \& Carvalho (1989) observaram, em Londrina, um parasitismo de D. speciosa por C. bosqi de $15 \%$ em média. Outro parasitóide observado em adultos de D. speciosa foi Centisfes sp. (Hymenoptera: Braconidae) (Gassen 1986). A ocorrência dos fungos Beauveria bassiana (Bals.) Vuill. e Metarhizium anisopliae (Metsch.) Sorok. em D. speciosa foi relatada (Tonet \& Reis 1979, Gassen 1986). Segundo Hohmann \& Carvalho (1989), entre os fungos entomopatogênicos, B. bassiana ocorre em maior proporção, causando cerca de 5 a $10 \%$ de mortalidade natural do inseto. Nematóides da família Mermithidae também são citados como agentes de controle natural de $D$. speciosa (Gassen 1986, Ferraz \& Monteiro 1987).

O trabalho teve por objetivo identificar e quantificar a ocorrência de inimigos naturais de adultos de D. speciosa coletados em plantas olerícolas, ao longo do ano, na região de Pelotas, RS.

\section{Material e Métodos}

Adultos de D. speciosa foram coletados semanalmente, de maio de 1994 a abril de 1995, em duas áreas de produtores de hortaliças localizadas próximo à Pelotas, RS, (lat. $31^{\circ}, 52^{\prime} \mathrm{S}$, long. $52^{\circ}, 21$ 'W), utilizando-se um aspirador manual. Foram feitas amostragens durante 15 minutos em cada uma das seguintes hortaliças, de acordo com a época de plantio: alface (Lactuca sativa), abóbora (Cucurbita sp.), beterraba (Beta vulgaris), batata (Solanum tuberosum), batata doce (Ipomoea batatas), cenoura (Daucus carota), couve (Brassica oleracea var. acephala), couve brócoli (Brassica oleracea var. italica\}, couve chinesa (Brassica pekinensis), espinafre (Spinacia oleracea), feijão (Phaseolus vulgaris), mostarda (Brassica campestris), melão (Cucumis melo), milho (Zea mays) e pepino (Cucumis sativus). Nas culturas amostradas não foram utilizados inseticidas.
No laboratório de Entomologia da Embrapa-CPACT os insetos foram colocados em recipientes de plástico telados, onde permaneceram por 30 dias ou até sua morte, em câmara climatizada $\left(25 \pm 2^{\circ} \mathrm{C}\right.$, UR $70 \pm 10 \%$ e fotofase de 14 horas). Em cada recipiente foram colocados dois insetos, independente do sexo, que receberam como alimento cenoura crua, trocada duas ou três vezes por semana. Larvas e/ou pupas de taquinídeos e braconídeos foram colocados em areia até a obtenção dos adultos; os nematóides foram conservados em álcool 70\%. Os inimigos naturais foram separados inicialmente ao nível de família e exemplares foram enviados à especialistas para identificação. Insetos mortos com sintomas de fungo foram colocados em câmara úmida até a esporulação. Com os resultados obtidos realizou-se o cálculo dos índices faunísticos de freqüência e constância (Silveira Neto et al. 1976), segundo os quais uma espécie pode ser constante (presente em mais de 50\% das coletas), acessória (presente em $25-50 \%$ das coletas) ou acidental (presente em menos de $25 \%$ das coletas).

\section{Resultados e Discussão}

O total de adultos de D. speciosa avaliados foi 4.775, sendo que 959 estavam parasitados, resultando em uma média anual de aproximadamente $20 \%$, índice expressivo já que ocorreu através do ano em plantas de marcada sazonalidade. Dentre os inimigos naturais identificados, 58,2\% foram do taquinídeo C. bosqi, $8,1 \%$ do braconídeo Cenistes gasseni Shaw, 2,8 \% do nematóide Hexamermis sp., 29,1\% do fungo B. bassiana e $1,8 \%$ de $M$. anisopliae. Os inimigos naturais considerados constantes, estando presentes em 90,4, 57,7 e $84,6 \%$ das amostras foram, respectivamente, C. bosqi, C. gasseni e B. bassiana. Hexamermis sp. e $M$. anisopiiae estiveram presentes em 26,9 e $25 \%$ o das amostras, respectivamente, sendo por isso consideradas espécies acessórias.

Através da média mensal de parasitismo, independente da espécie de inimigo na- 


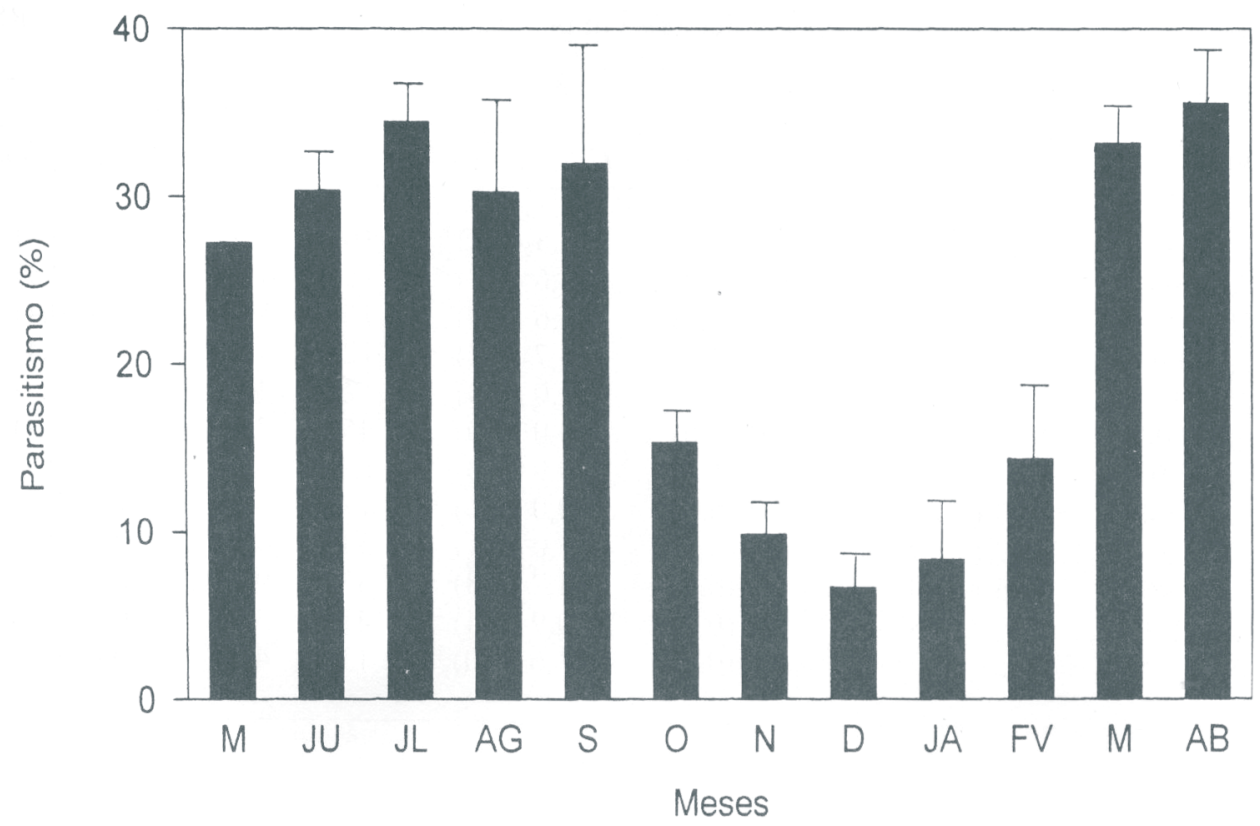

Figura 1. Média mensal (\%) de ocorrência de inimigos naturais de adultos de Diabrotica speciosa coletadas em plantas olerícolas na região de Pelotas, RS.

tural (Fig. 1), verificou-se que entre os meses de maio e setembro a percentagem média de parasitismo ficou em torno de $30 \%$, diminuindo entre outubro e fevereiro. O maior percentual foi observado em abril (35,5\%), valor que se aproxima do observado por Magalhães \& Quintela (1987), que analisaram apenas C. bosqi em adultos de C. urcuata, e é praticamente o dobro do descrito por Hohmann \& Carvalho (1989), para o mesmo parasitóide em adultos de D. speciosa. Em dezembro o parasitismo foi de apenas $6,6 \%$.

A ocorrência de C. bosqi atingiu índices superiores a $60 \%$ do total de parasitismo de maio a setembro de 1994 e abril de 1995, sendo que neste último mês o índice foi de $84,5 \%$. O menor valor foi observado no mês de dezembro $(1,7 \%)$ (Tabela 1). Este parasitóide abandona o hospedeiro na forma de larva, empu- pando $\log$ o a seguir no solo ou, por vezes, dentro do corpo do inseto, que fica oco. O inseto permanece vivo até momentos antes da saída do parasitóide.

A frequiência de ocorrência de C. gasseni variou entre $18,9 \%$ em dezembro e $1,5 \%$ em fevereiro (Tabela 1), não tendo sido observado nos meses de outubro, março e abril. Ao abandonar o hospedeiro na forma de larva, deixao com o aspecto inalterado. O nematóide $\mathrm{He}$ xamermis sp. ocorreu em índices pouco expressivos quando comparado aos demais inimigos naturais, não tendo sido encontrado nos meses de outubro, novembro e dezembro. Sua maior incidência foi no mês de julho, com índice de 5,6\% (Tabela 1). Observou-se que o inseto pode ser parasitado por mais de um nematóide, de diferentes tamanhos, que ao deixarem o hospedeiro ainda encontravam-se em 
Tabela 1. Frequiência média mensal e parasitismo observado (\%) de parasitóides e patógenos de adultos de Diabrotica speciosa coletados em plantas olerícolas na região de Pelotas, RS.

\begin{tabular}{lcrlllll}
\hline & \multicolumn{3}{c}{ Parasitóides } & & \multicolumn{2}{c}{ Patógenos } \\
\cline { 2 - 3 } \cline { 6 - 7 } Mês & C. bosqi & C. gasseni & Hexamermis & & B. bassiana & M. anisopliae \\
\hline MAI 94 & $77,4(21,1)$ & $9,3(2,5)$ & $2,5(0,7)$ & & $10,8(2,9)$ & $0,0(0,0)$ \\
JUN 94 & $62,8(19,0)$ & $18,1(6,0)$ & $2,6(0,7)$ & & $15,3(4,3)$ & $1,2(0,3)$ \\
JUL 94 & $66,6(22,8)$ & $11,8(4,1)$ & $5,6(2,0)$ & & $15,0(5,1)$ & $1,0(0,4)$ \\
AGO 94 & $72,2(21,2)$ & $13,0(3,1)$ & $1,7(0,7)$ & & $12,0(4,8)$ & $1,1(0,4)$ \\
SET 94 & $71,3(23,9)$ & $11,1(1,0)$ & $1,0(0,4)$ & & $12,2(4,9)$ & $4,4(1,7)$ \\
OUT 94 & $48,9(7,5)$ & $0,0(0,0)$ & $0,0(0,0)$ & & $45,6(7,1)$ & $5,5(0,7)$ \\
NOV 94 & $11,1(1,2)$ & $14,9(1,3)$ & $0,0(0,0)$ & & $68,1(6,6)$ & $5,9(0,7)$ \\
DEZ 94 & $1,7(0,1)$ & $18,9(0,8)$ & $0,0(0,0)$ & & $77,9(5,5)$ & $1,5(0,2)$ \\
JAN 95 & $34,9(2,9)$ & $6,0(0,4)$ & $5,0(0,1)$ & & $54,1(4,9)$ & $0,0(0,0)$ \\
FEV 95 & $40,5(4,0)$ & $1,5(0,3)$ & $4,7(0,8)$ & & $53,3(9,2)$ & $0,0(0,0)$ \\
MAR 95 & $57,9(18,8)$ & $0,0(0,0)$ & $0,9(0,4)$ & & $41,2(13,9)$ & $0,0(0,0)$ \\
ABR 95 & $84,5(30,2)$ & $0,0(0,0)$ & $3,6(1,0)$ & & $11,9(4,3)$ & $0,0(0,0)$ \\
& & & & & & \\
\hline
\end{tabular}

fases imaturas. Por isso, os exemplares enviados para identificação eram todos juvenis, não sendo possível a confirmação da espécie pela indisponibilidade de adultos.

O fungo $B$. bassiana ocorreu entre maio e setembro, em índices pouco superiores a $10 \%$. A partir de outubro houve um aumento gradual neste percentual, atingindo um máximo em dezembro $(77,9 \%)$ e decrescendo nos meses de janeiro, fevereiro e março até atingir valores pouco superiores a $11 \%$ em abril (Tabela 1). A umidade relativamente alta (acima de $70 \%$ na maior parte do ano), freqüente na região de Pelotas, associado ao aumento da temperatura média no mês de dezembro, provavelmente propiciou melhores condições para o desenvolvimento do fungo. Embora $B$. bassiana tenha ocorrido em percentual bastante elevado em dezembro, verificou-se que este foi o mês em que o número total de insetos parasitados foi menor (Fig. 1). Admite-se, portanto, que a ocorrência natural do fungo não causaria uma redução significativa na população do inseto. M. anisopliae não foi observado em alguns meses do ano, sendo que sua maior ocorrência $(5,9 \%)$ foi em novembro (Tabela 1$)$. Conforme relatado por Hohmann \& Carvalho (1989), entre os fungos entomopatogênicos a espécie B. bassiana foi a mais freqüente.

Com base nestes resultados, conclui-se que C. bosqi, B. bassiana e C. gasseni são os inimigos naturais encontrados com maior freqüência sobre adultos de D. speciosa, apresentando maior potencial para uso em programas de controle biológico.

\section{Agradecimentos}

Aos funcionários Jair Z. Farias e José C. Silveira, Embrapa-CPACT, pela ajuda na coleta do material. Ao Dr. Robert A. Wharton (Texas A\&M University) pela identificação do braconídeo; ao Dr. José H. Guimarães (USP) pela identificação do taquinídeo; aos Drs. Nora B. Camino (CEPAVE) e Luiz C. B. Ferraz (ESALQUSP) pela identificação do nematóide. Ao CNPq pelo auxílio financeiro. 


\section{Literatura Citada}

Ferraz, L. C. C. \& A. R. Monteiro. 1987. Sobre a ocorrência de mermitídeos parasitando insetos no Brasil. Nematol. Bras. 11:29-30.

Gassen, D. N. 1986. Parasites, patógenos e predadores de insetos associados à cultura do trigo. EMBRAPA, CNPFT, Circ. Téc. 1,86 p.

Hohmann, C. L. \& S. M. Carvalho. 1989. Pragas e seu controle. In O feijão no Paraná. IAPAR, Circ.Téc. 63,303p.

Magalhães, B.P. \& E.D. Quintela. 1987. Níveis de parasitismo de Urosigalphus chalcodermi Wilkinson sobre Chalcodermus bimaculatus Fiedier e de Celatoria bosqi Blanchard sobre Cerotoma arcuata Olivier em caupi (Vigna unguiculata (L.)
Walp.) em Goiás.An. Soc.Entomol. Brasil 16:235-238.

Silva, A. G. D. A., C. R. Gonçalves, D. M. Galvão, A. J. L. Gonçalves, J. Gomes. M. N. Silva \& L. Simoni. 1968. Quarto catálogo dos insetos que vivem nas plantas do Brasil, seu parasites e predadores. Rio de Janeiro, Min. Agric., Tomo 1, Parte $2,622 \mathrm{p}$.

Silveira Neto, S., O. Nakano, D. Barbin \& N. A. Vilia Nova. 1976. Manual de ecologia dos insetos. São Paulo, CERES, 419 p.

Tonet, G. L. \& E. M. Reis. 1979. Patogenicidade de Beauveria bassiana em insetos-pragas da soja. Pesq. Agropec. Bras. 14:89-95.

Recebido em 30/05/96. Aceito em 27/01/97. 